\title{
A provisional model of mathematical problem solving
}

\author{
DALE DINNEL, JOHN A. GLOVER, and ROYCE R. RONNING \\ University of Nebraska, Lincoln, Nebraska
}

\begin{abstract}
The current paper introduces a provisional model designed to describe the cognitive processes involved in solving algebraic and more complex mathematical problems. The model contains three major components: (1) the problem task environment, (2) long-term memory, and (3) working memory. Each of the major components consists of major processes and subprocesses that are described. Questions about the specificity of models are raised in the discussion.
\end{abstract}

The current paper introduces an information-processing model for mathematical problem solving. Although the model is provisional, it provides an approximate description of the cognitive processes involved in solving algebraic (and more complex) problems and offers a starting point in the search for more refined approaches. The model is based on similar models developed to depict reading processes (e.g., Gough, 1972; Just \& Carpenter, 1980; LaBerge \& Samuels, 1974) and writing processes (e.g., Hayes \& Flower, 1980). In addition, the model was constructed to fit the results of studies that have examined the cognitive processes and knowledge structures underlying mathematical ability (Davis, 1982; Greeno, Magone, \& Chaiklin, 1979; Larkin, McDermott, Simon, \& Simon, 1980; Mayer, 1981; Resnick, 1976). The proposed model is shown in Figure 1.

The model contains three major components (1) the problem task environment, (2) long-term memory, and (3) working memory. Each will be discussed in turn.

\section{PROBLEM TASK ENVIRONMENT}

The problem task environment serves two major functions, providing an external information access and furnishing an external or paper memory (notes) for information generated by the problem solver. The external information access includes the problem itself, directions and goals, tables (if necessary), notes or sample problems, and related text materials. The external memory serves as a (usually) written record employed to make available for examination partial solutions, facts from long-term memory useful in solving the problem, and notes concerning the process of solving the specific problem. In our view, both the external information access and the external storage are active (i.e., modifiable). The problem solver may alter sources of external

The authors' mailing address is: Department of Educational Psychology, Teachers College, University of Nebraska, Lincoln, NE 68588-0440. information as a problem is worked on and will reevaluate the salience of this information during the solution process. Depending upon problem complexity, external storage may vary from no or very limited use to being the major source of information for continuing with a problem. In any complex problem, however, we posit a continued updating of external storage. In general, we are proposing that the problem task environment (which may be modified to include motivational and affective components) interacts with the other two major components of the model in an iterative fashion.

\section{LONG-TERM MEMORY}

The long-term memory component of the model contains knowledge of math facts (e.g., $4+4=8$ ) and processes (e.g., subtraction). In addition, generalized problem types (e.g., the general form of the quadratic equation) and heuristics (Woods, Resnick, \& Groen, 1975) or algorithms (Clement, 1979) are also held in long-term memory. This information can be accessed by the problem solver in order to develop a problem-solution strategy and to perform the operations necessary for a solution. Information from long-term memory may be accessed and employed in the working memory, or it may be accessed, held briefly in the working memory, and then placed into the external memory storage in the problem task environment.

\section{WORKING MEMORY}

The most active component of the model is in working memory. We envision mathematical problem solving in working memory as consisting of three major processes (representation, planning, reporting) that are highly interactive.

\section{Representation of the Problem}

Representation of the problem involves three subprocesses: reading and interpreting, retrieving, and goal setting. The function of representing the problem is to 


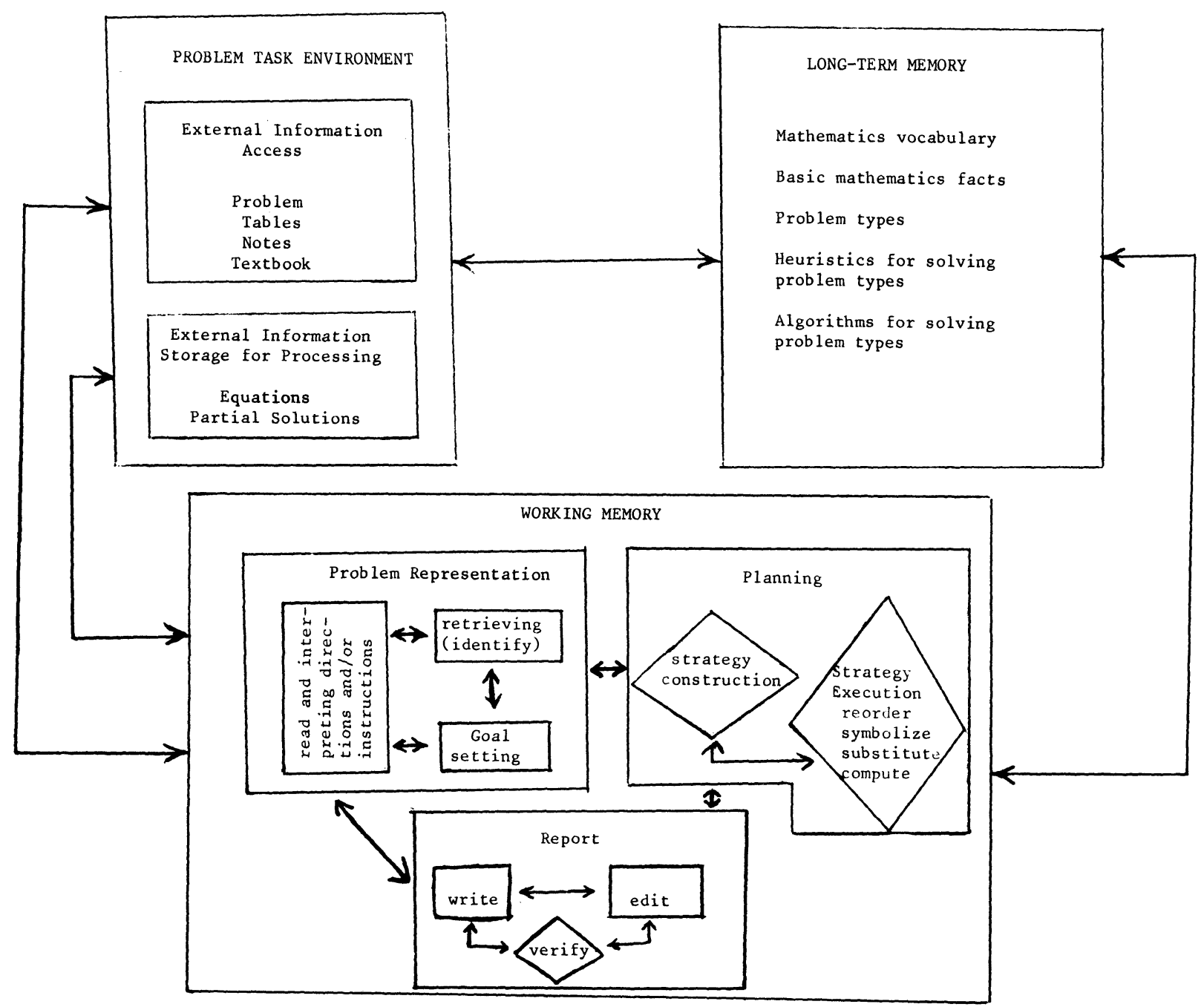

Figure 1. A provisional mathematical problem-solving model.

take information from the problem task environment and long-term memory in order to understand what the problem demands are and thus to set goals for problem solution.

Reading and interpreting. The subprocess of reading and interpreting permits the decoding and comprehension of the problem. As a subprocess in the current model, reading and interpreting is given relatively little apparent weight. In our view, however, this subprocess is representative of the far more detailed components of a reading model such as that proposed by Just and Carpenter (1980). The subprocess of reading and interpreting, then, is interactive with both the problem task environment and the long-term memory, employing (at least at the outset) a considerable proportion of the working memory's capacity. Differences between reading prose and reading and interpreting mathematical information should be kept in mind, however. According to Briars (1983), these differences include the flexibility of mathematical symbols (i.e., variables can mean dif- ferent things in different contexts) and the lack of redundancy of mathematical language. An additional function of the reading and interpreting subprocess that points to a difference from reading models is the potential shift of information from one modality (e.g., acoustic) to another (e.g., visual). Although this function may not occur for all mathematical problems, it seems that the interpretation of many problems found in algebra and more complex courses may involve such a modality shift (Michener, 1978).

Retrieving. The second subprocess within representation is retrieving. Through this subprocess, information relevant to the problem is obtained from long-term memory. The importance of retrieval of materials more complex than "math facts" has been noted in studies of how individuals solve thermodynamics problems (Bhaskar \& Simon, 1977) and physics problems (Larkin, 1980). Furthermore, Michener (1978) asserted that a great deal of mathematics knowledge is stored in longterm memory via key examples or problem types. 
Implicit in the retrieval process of problem types or key examples is the retrieval of a generalized heuristic or algorithm for solving the problem. We do not suggest that the retrieval of a heuristic or algorithm is ensured by the retrieval of a problem type. However, the problem type may serve as a cue for retrieving the appropriate heuristic.

Goal setting. The third subprocess within representation of the problem is goal setting. This subprocess is employed in selecting criteria from the problem task environment and/or long-term memory for use in evaluating the problem solution as well as intermediate solutions. Representing the problem is highly interactive with the planning process (Bhaskar \& Simon, 1977; Davis, 1982; Greeno, 1976, 1978).

\section{Planning}

The major process of planning consists of two subprocesses, strategy construction and strategy execution.

Strategy construction. The subprocess of strategy construction is, as we have noted, highly interactive with goal setting. The function carried out by the strategy-construction subprocess is the transformation of heuristics or algorithms in long-term memory or the transformation of heuristics or algorithms gained from the problem task environment so that they may be employed to solve the problem. Conversely, this subprocess may instead involve the transformation of the problem so that it matches up to specific algorithms or heuristics. As we envision it, this subprocess may vary from the simple selection of an algorithm that will guarantee a correct solution if properly employed, to the construction of an entire strategy based on the transformation of heuristics and the problem itself until the problem attains a solvable form. We also suggest, however, that strategy construction need not lead to a complete solution of the problem. The problem solver may not possess, or be able to access in the problem task environment, sufficient information to solve the problem. Furthermore, problem and/or heuristic and algorithm transformation may simply result in a restatement of the problem, which would then require a reexecution of problem-solution strategies. As strategy construction proceeds, the goals for solving the problem may be revised on several occasions, depending on the nature of the transformations.

Strategy execution. The second subprocess in planning is the actual execution of a strategy or strategies. This process may be activated on several occasions during a problem-solving episode. That is, it may be employed to test the selection of a strategy or to complete a partial solution to a problem that would then be stored in external memory, or it may result in the final solution to a problem. The execution subprocess is closely linked to the strategy-construction subprocess and to the reporting process. Furthermore, it draws heavily on long-term memory. In execution, the information provided in the problem may be reordered, symbolized, substituted for, or changed into another modality. It is in this subprocess that the actual calculations occur and, thus, a great deal of information manipulation results.

\section{Reporting}

The reporting process, the third of the processes envisioned for working memory, functions to take material from memory under the guidance of the strategy selected and to place it into the problem task environment. The reporting process may come into play several times during the solution of a problem as tentative or partial solutions are generated. Three subprocesses are involved in reporting: writing, verifying, and editing.

The writing subprocess involves the actual generation of information into acceptable solution statements (either prose or mathematical symbols). The verifying subprocess involves rechecking the solution statements by employing, at least in part, the criteria developed in goal setting, information from the external information access, and basic facts from long-term memory. The editing process involves making changes called for in the verification subprocess.

\section{DISCUSSION}

The model presented here is provisional. It has been designed to serve as a guide for the further development of models and for work in examining individual differences in informationprocessing abilities among students. Following the work of Hunt (e.g.,1978) on individual differences in processing abilities among "high" and "low" verbals, it would seem that such a model would allow for the testing of several potential differences among students with varying levels of competence in mathematics. For example, we would predict differences among students in the functions carried out in the execution subprocess. That is, we would expect that competent mathematics students would be better (i.e., more rapidly, more accurately) able to reorder information in working memory, to shift from one mode of information to another, to hold ordered information in working memory, and to transpose information from one symbol system to another.

The model proposed here may serve other functions. If it were used as a basis for examining protocols of problem-solution attempts in mathematics, it could provide a framework for evaluating and classifying solution responses. At the same time, feedback from the behavior of mathematical problem solvers may be used to modify or verify this provisional model. Thus, the model may serve as a source of hypotheses about mathematical problem-solving behavior.

More broadly, we believe that the model provides another step in modification of the general problem-solving (GPS) model developed by Newell and Simon (1972) and others. The inability of GPS to deal with all of problem solving has long been recognized. The now widespread recognition that problem solving is to some (perhaps large) degree knowledge specific makes necessary the development of a number of problem-solving models in various knowledge domains. A logical and theoretical question yet unanswered is the degree of specificity required by a model. Are models of the reading or writing process, or of problem solving in science and mathematics, general enough to cover the wide array of reading, writing, or problem solving required in these areas? Or must still more specific models be developed for, say, problem solving with the calculus as opposed 
to problem solving in topology in mathematics? Formulation and scrutiny of clearly conceptualized models permits one line of attack that may help to deal with this significant issue.

\section{REFERENCES}

Bhaskar, R., \& Simon, H. A. (1977). Problem solving in semantically rich domains: An example from engineering thermodynamics. Cognitive Science, 1, 193-215.

BriARS, D. J. (1983). An information-processing analysis of mathematical ability. In R. F. Dillon \& R. R. Schmeck (Eds.), Individual differences in cognition (pp. 181-204). New York: Academic Press.

Clement, F. (1979). Patterns of Joey's comments on arithmetic problems. Journal of Children's Mathematical Behavior, 2, 58-68.

DAVIS, R. B. (1982, March). Representations and judgments in mathematical thought. Paper presented at the meeting of the American Educational Research Association, New York.

Gough, P. G. (1972). One second of reading. In J. F. Kavanagh \& I. G. Mattingly (Eds.), Language by eye and ear (pp. 331-358). Cambridge, MA: MIT Press.

Greeno, J. G. (1976). Cognitive objectives of instruction: Theory of knowledge for solving problems and answering questions. In D. Klahr (Ed.), Cognition and Instruction (pp. 123-159). Hillsdale, NJ: Erlbaum.

Greeno, J. G. (1978). Understanding and procedural knowledge in mathematics instruction. Educational Psychologist, 12, 262-283.

Greeno, J. G., Magone, M. E., \& Chaiklin, S. (1979). Theory of constructions and set in problem solving. Memory \& Cognition, 7, 445-461.
Hayes, J. R., \& Flower, L. S. (1980). Identifying the organization of writing processes. In L. W. Gregg \& E. R. Steinberg (Eds.), Cognitive processes in writing (pp. 3-30). Hillsdale, NJ: Erlbaum.

Hunt, E. (1978). Mechanics of verbal ability. Psychological Review, 85, 109-130.

Just, M. A., \& CArpenter, P. A. (1980). A theory of reading: From eye fixations to comprehension. Psychological Review, 87, 329-354.

LaBerge, D., \& Samuels, S. J. (1974). Toward a theory of automatic information processing in reading. Cognitive Psychology, 6, 293-323.

LARKIN, J. H. (1980, October). Models of skilled and less skilled problem solving in physics. Paper presented to the NIE-LRDC Conference on Thinking and Learning Skills, Pittsburg.

Larkin, J. G., McDermott, J., Simon, D. P., \& Simon, H. A. (1980). Models of competence in solving physics problems. Cognitive Science, 4, 317-345.

MAYER, R. E. (1981). Frequency norms and structural analysis of algebra story problems into families, categories, and templates. Instructional Science, 10, 135-175.

Michener, D. R. (1978). Understanding mathematics. Cognitive Science, 2, 361-383.

Newell, A., \& Simon, H. A. (1972). Human problem solving. Englewood Cliffs, NJ: Prentice-Hall.

RESNICK, L. B. (1976). Task analysis in instructional design: Some cases from mathematics. In D. Klahr (Ed.), Cognition and instruction (pp. 51-80). Hillsdale, NJ: Erlbaum.

Woods, S. S., Resnick, L. B., \& Groen, G. J. (1975). An experimental test of five process models for subtraction. Journal of Educational Psychology, 67, 17-21.

(Manuscript received for publication April 16, 1984.) 